\title{
Intrapersonal Conflict of a Teacher as a Determinant of his Professional Development
}

\author{
Mergalyas Kashapov \\ Doctor of Psychological Sciences, Professor, Head of the Department of Pedagogics and \\ Pedagogical Psychology, P.G. Demidov Yaroslavl State University; smk007@bk.ru
}

\section{Svetlana Tomchuk}

Candidate of Psychological Sciences, Associate Professor, Head of the Department of Humanities Yaroslavl Institute of Education Development; Chuk66@yandex.ru

\section{Tatiana Ogorodova}

Candidate of Psychological Sciences, Associate Professor of the Department of Pedagogical Psychology and Pedagogy P.G. Demidov Yaroslavl State University; shtak@bk.ru

\section{Doi:10.5901/mjss.2015.v6n6s5p186}

\begin{abstract}
The aim of the research is to study the impact of intrapersonal contradictions of the teacher in his further professional development and self-improvement. The study used the following methods: the method of studying self-assessment; a questionnaire to determine the level of professional pedagogical thinking; "Integrative Anxiety Test"; the method of "Study of Self-concept." It was revealed that teachers with a high level of internal conflict tend to have two opposing fields that characterize a person from the positive side (self-worth, self-leadership, self-confidence) and a negative (self-accusation, closeness). Acquiring professional skills, the level of intrapersonal conflicts of teachers is being increased, although seemingly gained professional experience should give teachers more confidence. The findings suggest the self-criticism of teachers, the conflict between the "I" -Real and "I" -Perfect, developed reflection. To solve their intrapersonal contradictions and conflicts, the teachers mostly use metacognitive strategies of decisions; they have dominated supra-situational level of professional pedagogical thinking. Qualitative analysis of the results of the study revealed a high correlation between intrapersonal conflict and supra-situational level of professional pedagogical thinking leads to the conclusion that it is a highly intrapersonal conflict that is a determinant of professional formation and development of the teacher.
\end{abstract}

Keywords: intrapersonal conflict, professional development of a teacher.

\section{Introduction}

In the transition to the information society, changing of educational paradigms there are increased requirements to the education system as a whole, and to the competence of teachers and the effectiveness of his professional activity. V.D. Shadrikov emphasizes that the system of vocational pedagogical education like no other one, is exposed to the influence of external environment, and in a high instability of the environment, fast and poorly projected changes in the society and in the education system it is potentially capable of ensuring the preservation of a common educational space. Systemgenetic approach developed by V.D. Shadrikov, is aimed at understanding all these aspects of the system linking the levels of development of the individual with the structure of the education system and mode of operation, which is necessary to prepare the subjects of educational activity (Shadrikov, 2013). But the constant changes in society and education, changing the system of value orientations have a negative effect on the personality of a teacher, they create psycho-emotional tension and disturb the natural tendency of the individual to stability. All this leads to permanent intrapersonal contradictions and conflicts in the professional work of the teacher.

\section{Literature Review on the Issue of an Intrapersonal Conflict of the Teacher}

In modern studies teacher's professional development is considered as a complex and contradictory dynamic process, determined by the internal activity of the teacher's personality. Undoubted contribution to the psychology of professional development is made by the concept of professional pedagogical thinking of M.M. Kashapov based on the activity 
approach. The author identifies the problematic as the basic unit of analysis of pedagogical thinking, which is determined as a result of pedagogical conflicts caused by external factors and intrapersonal factors (Kashapov, 2011).

Intrapersonal conflict is a condition characterized by the presence of a person and mutually contradictory motives, values and goals, the state of the internal structure of the personality, characterized by antagonism of its elements. Such conflicts are characterized by confrontation between the two which start in the human soul, they are perceived with tension, experienced emotionally and require resolving and overcoming.

The problem of intrapersonal conflicts is paid attention by the representatives of various areas of foreign and national psychology. Carl Rogers, a representative of the humanist school, considers the theory of the intrapersonal conflict as "the dissonance between" I-concept ", on the one hand, and the ideal -" I ", on the other» (Rogers \& Dymond, 1954).

Abraham Maslow, a leading representative of humanistic psychology, defined the essence of the intrapersonal conflict in the gap "between the desire for self-actualization and the actual result: a person tends to be what he can be, but it is not always possible» (Maslow, 1954). According to the concept developed by the Austrian psychologist Viktor Frankl, the main driving force of every human life is to find the meaning of life and the struggle for it "the lack of meaning of life causes a human such condition which he calls an existential vacuum or a sense of purposelessness and emptiness," which leads to intrapersonal conflict (Frankl, 1967).

Modern foreign scientists are considering intrapersonal conflict from the point of existential psychology. The crisis of hope and search for meaning, the eternal questions of responsibility for their actions - M. Mahoney describes these challenges in terms of "essential tension" and the dialectical development that they make possible (Mahoney \& Mahoney, 2001). Existential problems due to the fact that they set the task of a choice, are often formulated in the form of life dilemmas such as "happiness - suffering"; "The fear of death - the involvement in the life"; "Free choice - commitment to life reality"; "The meaning of life - meaningless» (Jacobsen, 2007). But "dichotomization" of existential problems gives them a flat image, when in fact their bipolarity creates tension, which requires a "third" solution. Thus, the existential problems of an individual is the problem rather of "three-dimensional" space design solution in which there is no preference or rejection of one of the obvious choice, but the alternative to select when it is necessary to rise above the situation, using metasubject strategy. Moreover, modern scholars emphasize the opportunity at each stage of the intrapersonal conflict reorienting it in a positive direction (Deutch, 1973).

Russian scientists are considering intrapersonal conflict from the point of unjustified expectations, as the state of lengthy disintegration of the personality, which is expressed in the exacerbation of the contradictions between the various manifestations of personality. At the same time, they stress that intrapersonal conflict is an inevitable part of the structure of a personality. Anyone even having the leading motives of behaviour and the main goal in life, cannot have only one purpose or motive, therefore, intrapersonal conflict of particular interests and goals is quite normal for each individual event.

Thus, the vast majority of theories in the national and foreign psychology consider the problem of the driving forces of the development of the individual through overcoming and resolving conflicts, "localized" in his inner world. Moreover, the need for reorientation of the conflict at every stage of its development in a positive direction is emphasized, so motivational focus on constructive resolution is acquiring an important meaning.

\section{Research Instrument}

The purpose of the research is the study of the influence of intrapersonal contradictions of the teacher on his further professional development and self-improvement.

Hypothesis of the research:

- The source of intrapersonal contradictions of the teacher is a mismatch between the "I" -Real and "I" -Perfect, between the level of inflated claims and actual achievements, which leads to the recognition of his inferiority. The teacher considers mostly himself to be the real source of his successes and failures.

- Teachers with a high level of intrapersonal conflicts have a high level of anxiety, so anxiety is an indirect sign of intrapersonal contradictions.

- The successful resolution of intrapersonal contradictions of teachers will be favoured by the use of metacognitive strategies, solutions that will lead to a professional change and self-improvement of teachers.

Tasks of the research:

- Determine the indicators of intrapersonal conflict in cognitive, emotional, behavioral spheres and choose methods for their diagnosis. 
- Identify the levels of intrapersonal conflict of teachers, consider the dynamics of change in intrapersonal conflicts of teachers at different stages of professionalization.

- Reveal features of internal conflicts of teachers with different levels.

- Define conditions for a constructive resolution of intrapersonal contradictions and further professional development of the teacher.

\section{Research Methods}

The indicators of intrapersonal conflict according to A.J. Antsupov and A.I. Shipilov are the following:

- In the cognitive sphere - a problem of a value choice, low self-esteem;

- In the emotional sphere - emotional stress, increased levels of anxiety;

- In the field of behavior - reduced satisfaction with one's activities (Antsupov, Shipilov, 2004).

The bulk of the sample consisted of teachers of the humanities - 163 teachers working in the educational institutions of various types of Yaroslavl region, aged from 24 to 63 years old, the study was conducted from 2011 to 2014.

The formation of the teacher as a professional is influenced by many factors, the most significant of them are teaching experience and peculiarities of professional and educational activities in a certain period of work, so this factor was taken into account in this research.

According to the figures for the experimental research of peculiarities of intrapersonal conflicts of teachers were selected by the following methods:

- For the study of cognitive sphere - the methods self-assessment research; a questionnaire to identify situational and supra-situational level of professional pedagogical thinking;

- For the study of the emotional sphere - testing methods "Integrative Test of Anxiety";

- For the study of behavioral sphere - methods "Study of Self-concept"

\section{Results of the Research and Discussion}

On the first stage the methods of self-concept was used.

This technique allows obtaining data on nine scales: "closeness", "confidence", "self-leadership", "reflected selfconcept", "self-worth", "self-acceptance", "self-attachment", "internal conflict", "self-accusation".

On the basis of the data obtained on the scale of "internal conflict", three continuum were formed.

Group1 - teachers with a high level of internal conflict (HIC). Higher index of internal conflict corresponds to the person who has negative attitude to himself. He is in the condition of a constant control of his "I", he is committed to a deep assessment of everything that is happening in his inner world. Subjects with high values of internal conflict are characterized by high demands to themselves, which often leads to a conflict between "I"-real and "I"- ideal, between the level of claims and actual achievements, to the recognition of their inferiority. They consider mostly themselves to be the true source of their successes and failures.

Group 2 - teachers with a medium level of internal conflict (MIC). The medium index of internal conflict is typical of a person whose attitude to himself, the attitude to see himself depends on the degree of adaptability in the situation. In the usual conditions which features are familiar and predictable, there is a positive self-attitude, the recognition of one's merits and appreciation of achievements. Unexpected difficulties, encountered obstacles may lead to strengthen the underestimation of one's success.

Group 3 - teachers with a low level of internal conflict (LIC). The low index of internal conflict is more common among those who are generally positive about themselves, feel the balance between their abilities and the requirements of the surrounding reality, between aspirations and achievements, and are satisfied with a current life situation. At the same time a denial of problems and superficial perception of oneself is possible.

In determining the relationship of internal conflict of a teacher and his working experience it was found that young professionals have the lowest level of internal conflict, they have a positive attitude to themselves, they are satisfied with the current life situation and themselves, but apparently, taking into account their adaptation period, it is affected by superficial perception of themselves and the denial of their problems. In the first two periods of professional activity (1-5 and 5-15 years) there is a low level of internal conflict, the last two stages - a high level of internal conflict, although seemingly gained professional experience should give them confidence. The findings suggest that the prevalence of 
negative attitudes towards themselves, deep assessment of everything that is happening in the inner world, the presence of a conflict between the "I" -Real and "I" -Perfect, developed reflection.

On this stage, the study establishes a correlation of the scale of "internal conflict" with the performance of eight different scales of the methods of a self-concept study using the Spearman rank correlation coefficient.

In the study group 1 - teachers with HIC revealed a positive relationship between indicators of the scale of the "internal conflict" and the figures for other scales: "closed» $(r=0,48, p<0,001)$, «self-value» $(r=0,32, p<0.01)$, "selfleadership» $(r=0,52, p<0,001)$, «arrogance» $(r=0,36, p<0,01)$, «self-accusation» $(r=0,25, p<0.05)$ (Fig. 1).

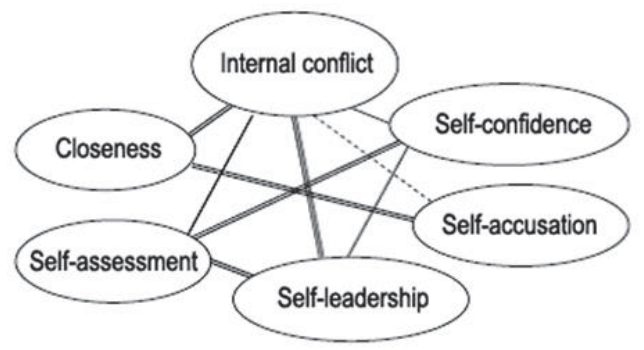

Figure 1. The Scheme of correlations of group1 - teachers with HIC between indexes of the scale "internal conflict" and the figures for other scales.

Note: ---- The significance level of $p<0,05$; significance level of $p<0,01$; significance level of $p<0,001$.

Identified positive relationship indicates that the structure of internal conflicts with teachers with HIC there are two opposing spheres that characterize a person both from the positive side (self-worth, self-leadership, self-confidence) and from the negative (self-accustion, closeness). It is this dialectical opposition that is in the basis of inner conflicts of a personality.

In the study of group 3 - teachers with LIC a positive relationship between indicators of the scale of the "internal conflict" and the figures for other scales' self-attachment »( $(r=0,34, p<0,01)$, « self-confidence »( $r=0,28, p<0,01)$, «selfacceptance» $(r=0,25, p<0,05)$ is revealed (Fig. 2).

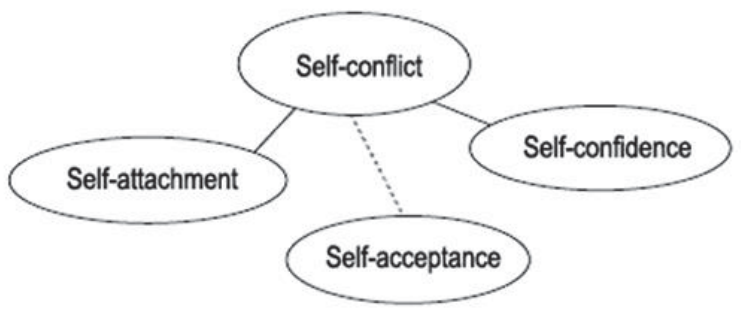

Figure 2. Scheme of correlations group3 - teachers with LIC between indicators of the scale of "internal conflict" and the figures for other scales.

Note: ----The significance level of $p<0,05$; significance level of $p<0,01$; significance level of $p<0,001$.

Identified positive correlation indicates that in the structure of internal conflicts of teachers with LIC there are no opposing spheres: teachers with LIC inhere self-esteem, "self-acceptance" with their inner motives, shortcomings and weaknesses.

On the 2nd stage of the research the data were correlated which were obtained by the methods of self-concept (MSC), with the data obtained by the methods of the study of self-assessment, in order to identify the adequacy of selfevaluation of different continua. In the study of the adequacy of self-assessment, it was found that a group of teachers with HIC is characterized by an adequate self-assessment (68\%) and a high percentage of teachers with low self-esteem (23\%). In the group of teachers with LIC adequate self-assessment also prevails, although this percentage is significantly lower (54\%), but there is quite a high percentage of teachers with high self-esteem (39\%). Teachers with HIC and MIC 
are increasingly characterized by adequate self-assessment that supposes the equal acceptance by the individual both his advantages and disadvantages. Self-confidence allows a person to regulate the level of claims and correctly assess one's capabilities for different situations. Cognizing and assessing oneself, an individual can more consciously control his behavior and go on in professional self-perfection.

At the same time in the course of the research it was revealed that teachers with LIC are mostly young professionals who have high self-esteem. We have already made a hypothesis that young professionals are satisfied with the current life situation and themselves, but, apparently, it affects their inadequate assessment. The findings confirmed this assumption: such teachers exaggerate their merits, set higher goals than those that they can really achieve, they have a high level of claims which does not correspond to their abilities. The absence or the lack of need for selfperfection impedes their further professional development.

On the 3rd stage of the research there was a correlation of the results obtained during the research with data from the study of the emotional sphere by test procedure "Integrative anxiety test." During the study we tested the hypothesis that a teacher with the HIC has a higher level of anxiety than teachers with LIC.

Integrative anxiety test (IAT) is an original questionnaire for subjective personal scaling or psychological diagnosis of emotional and personality traits of the subjects by allocating 5 additional components (subscales): emotional discomfort, asthenic component, phobic component, alarming assessment of the prospects, social protection.

When analyzing the emotional state of respondents, it was found that a group of teachers with HIC is dominated by high and medium levels of anxiety (respectively $41.7 \%$ and $45 \%$ ) a group of teachers with LIC is dominated by low and medium level of anxiety (respectively $46.7 \%$ and $43,2 \%$ ).

When studying group1 - teachers with HIC there was revealed a positive correlation of intrapersonal conflict with subscales "Integrative anxiety test": emotional discomfort $(r=0,52, p<0,001)$, asthenic component $(r=0,34, p<0,01)$, an alarming assessment of the prospects $(r=0,32, p<0,01)$. The findings suggest that teachers with HIC experience emotional discomfort in professional and personal lives, negative emotions take a large place in their lives, they worry about the nearest future. Thus, the hypothesis tested by us in the course of the research, that a teacher with HIC has higher levels of anxiety than teachers with LIC, was confirmed.

On the $4^{\text {th }}$ stage of the research there was conducted a survey on what contradictions of modern educational space cause the greatest difficulties to teachers in their professional work, what gives them the greatest concern.

After analyzing the responses of teachers, we have the following list of professional contradictions of teachers:

- a rapid change of new educational paradigms and methodological priorities in education, and absence of internal readiness of the teacher to implement them;

- availability of standards of education and a personal need of a teacher in creative self-realization and the ability to satisfy it;

- self-development, requiring efforts in acceleration of professional growth and self-preservation dictating the need for estimating the forces on the whole "life marathon";

- prevalent outlook of a teacher and a new understanding and the attitude of modern children, who are in conflict due to the rapid succession of social priorities.

On the 5th stage of the research it was important to find out which strategy of pedagogical thinking is chosen by teachers to solve their professional problems. For the diagnostics of situational and supra-situational level of professional pedagogical thinking (PPT) was used "a questionnaire to determine the dominant level of problem in solving pedagogical problematic situations." The study tested the hypothesis that teachers with HIC possess a supra-situational level of professional pedagogical thinking, whereas teacher with the LIC have a situational level of professional pedagogical thinking.

In the research it was found that a supra-situational level of professional pedagogical thinking (respectively $61 \%$ and $72 \%$ ) prevails in a group of teachers with $\mathrm{HIC}$ and MIC and a situational level of professional pedagogical thinking (77\%) dominates in the group of teachers with LIC.

Thus, teachers with HIC and MIC increasingly inhere a supra-situational level of professional pedagogical thinking, which confirms high creative potential of teachers, allowing them to deal with emerging problem situations based on the analysis of the causes and predict the results of their activities using non-standard strategies to address problem situations. 


\section{Conclusion}

Thus, in the course of the research the following results were obtained.

Teachers with little experience of pedagogical activity (1-5 years) possess the lowest level of intrapersonal conflict (23.4\%), apparently, due to their adaptation period; it is affected by the superficial perception of oneself and the denial of one's problems. Gaining more professional skills, the level of intrapersonal conflicts of teachers is increasing: in 5-15 years - 35.1\%, 15-25 years - 43.6\%, over 25 years - 45.9\%, although it would seem, acquired professional experience should give teachers more confidence. The findings suggest that the prevalence of negative attitudes towards themselves; self-critical evaluation of everything that is happening in the inner world; the presence of a conflict between the "l" -Real and "I" -Perfect, developed reflection.

In the structure of internal conflicts with teachers HIC there are two opposing spheres that characterize an individual both from a positive side (self-worth, self-leadership, self-confidence) and a negative side (self-accusation, closeness). It is this dialectical opposition that underlies the inner conflicts of a personality. Besides, it should be noted the unity, the stability of relations in the identified structure. In the structure of internal conflicts of teachers with LIC there are no opposite spheres. If to characterize a teacher with LIC, we can say that he has self-respect, "self-acceptance" with his inner motives, flaws and weaknesses and at the same time a desire to change in terms to his present state. It should be noted that there is fragmentation and instability of relationships in the identified structure.

In the analysis of the adequacy of self-assessment of respondents it was found that an adequate self-assessment of its professional capacity (68\%) is prevailed in a group of teachers with HIC, a high percentage of teachers with low self-esteem (23\%). The group of teachers with LIC also has adequate self-assessment, although this percentage is significantly lower (54\%), but there is a fairly high percentage of teachers with high self-esteem (39\%), indicating a fairly objective self-assessment of their professional capabilities.

In the study of emotional state it was found that the group of teachers with $\mathrm{HIC}$ is prevailed with high and medium levels of anxiety (respectively $41.7 \%$ and $45 \%$ ), and the group of teachers with the LIC is dominated by low and medium level of anxiety (respectively $46.7 \%$ and $43,2 \%$ ). In the study of teachers with HIC it was found a positive correlation of intrapersonal conflict with additional components (subscales) "Integrative anxiety test": emotional discomfort $(r=0,52, p$ $<0,001)$, asthenic component $(r=0,34, p<0,01)$, an alarming assessment of the prospects $(r=0,32, p<0,01)$. The findings suggest that teachers with HIC experience emotional discomfort in their professional and personal lives, negative emotions tke an important part in their lives, they worry about the nearest future. Our findings suggest that anxiety is an indirect sign of intrapersonal contradictions.

In the study of the dominant level of professional pedagogical thinking it was found that supra-situational level of professional pedagogical thinking (respectively $61 \%$ and $72 \%$ ) prevails in the group of teachers with HIC and MIC and the group of teachers with LIC is dominated by situational level of professional pedagogical thinking (77\%). Teachers with HIC and MIC increasingly inhere supra-situational level of professional pedagogical thinking, which confirms the high potential of creative teachers, allowing them to solve the problematic situations on the basis of an analysis of the causes and predict the results of their activities using non-standard strategies to solve problems. Domination of supra-situational level of professional pedagogical thinking of teachers with HIC indicates that they have to solve their intrapersonal contradictions and conflicts based on metacognitive strategies which is confirmed by studies carried out earlier (Tomchuk, 2007).

Awareness of their important issues, the experience of intrapersonal contradictions encourages teachers to explore new possibilities of self-realization, to perceive the characteristics of their own professional activity, the development of which will help to optimize the educational process. The active professional position, metacognitive strategies for solving conflicts and supra-situational level of professional pedagogical thinking of teachers lead to the transformation of the components of internal contradictions and make it possible to regard it as a prerequisite for further professional and personal development. An important condition to preserve the vector of development is the presence of a strongly expressed desire for a self-change and self-improvement to self-fulfillment, to spirituality, which puts teachers on a new circuit of professional development and is a constructive way to resolve the contradiction.

The high level of reflexive processes, aspiration for independent solution of psychological contradictions allows the teacher to overcome the experienced collision, qualitatively changing his professional activities. In general, we carried out a qualitative analysis of results which brings to the conclusion that high intrapersonal conflict is a determinant of professional formation and development of a teacher. 


\section{Acknowledgements}

The work was carried out with the financial support of the project № 25.2356.2014K within the project part of the state task to scientific research of the Institute of Higher Education.

\section{References}

Ancupov, A.Ya., Shipilov, A.I. (2004). Konfliktologiya [Conflictology]. Moskva: Yuniti.

Deutsch, M. (1973). The Resolution of Conflict: Constructive \& Destructive Processes. London: Yale University Press.

Frankl, V.E. (1967). Psychotherapy and existentialism. N.Y.: Simon and Schuster.

Jacobsen, B. (2007). Invitation to Existential Psychology: A Psychology for the Unigue Human Being and Its Applications in Therapy. England.

Kashapov, M.M. (2011). Psihologiya tvorcheskogo processa v konflikte [Psychology of the creative process in the conflict]. Monografiya. Yyroslavl: YarGU.

Mahoney, M., Mahoney, S. (2001). Living Within Essential Tensions: Dialectics and Future Development. Pierson.

Maslow, A.H. (1954). Motivation and Personality. Harper and Bros.

Rogers, C.R., Rosalind Dymond (1954). Psychotherapy and Personality Change. University of Chicago Press.

Shadrikov, V.D. (2013). Psihologiya deyatel'nosti cheloveka [Psychology of human activities]. M.: Izd-vo «lnstitut psihologii RAN».

Tomchuk, S.A. (2007). Sootnoshenie muzykal'nogo i pedagogicheskogo myshleniya v professional'noj deyatel'nosti uchitelya muzyki [Correlation of musical and pedagogical thinking in professional work of a music teacher]. Avtoreferat dissertacii kandidata psihologicheskih nauk. Yaroslavl. 